\title{
On the Expectation of Music Teachers in Music Psychology Education
}

\section{Junyi Chen}

\author{
Normal School of Music, Shandong University of Arts, Jinan, 250014, China
}

Keywords: Music, Psychological education, Music teacher.

\begin{abstract}
Music education plays a very important role in the cultivation of students' quality education, which has a positive effect on the psychological adjustment of students. Students as a social group in a more specific class of people, their life and learning process by many factors outside the impact. Students often encounter in the face of difficulties or setbacks, resulting in some difficult to self-regulation of psychological problems, the specific performance will produce fear and weariness of the emotions, and students and teachers get along well between, addicted to the network , And even took the road of crime and so on. But the student period for a person's future development is a crucial impact, so at this stage from the teacher to the parents should help students have a healthy mental state. And music from the beginning of the history of mankind with us in close contact with, and accompanied by the development process of mankind. Music is not only a medium to meet the needs of the human spirit, but also to help students to adjust the psychological tools. To make the performance of music psychology education is obvious, it is necessary for music teachers in the classroom to consciously guide students to help students establish a healthy and positive attitude. Based on the theory of music psychology education, this paper analyzes the specific requirements and expectations of music teachers in music psychology by enumerating the common psychological problems of students, taking the meaning and function of music psychology education as the theoretical basis.
\end{abstract}

\section{Foreword}

Music is a good expression of ideas and feelings of the media, for the surrounding atmosphere and people's ideas, will have a certain degree of influence, with absolute appeal and influence. Based on the excellent characteristics of music, from the last century, there have been countries to music as a way to treat patients with mental illness, it turns out that the music's guiding function, can help people to psychological adjustment, to help patients with mental illness Psychological counseling. Therefore, the music psychology education applied in the school, by the school teacher to the students of music knowledge teaching and music related skills training, thus helping students to improve their own comprehensive music quality and sentiment. Teachers can enrich the students' emotions and guide students' thoughts through the teaching of music, thus achieving the goal of perfecting students' personality and playing positive psychological adjustment of music. Music teacher as the output of music quality, in order to achieve the purpose of music psychology education, students need to feel and learn music in the process, to exert a good guide, need to pay attention to methods and strategies to carry out the teaching process. Therefore, the music teacher's position for the teacher's quality and quality of a certain request. 


\section{A Brief Introduction to Music Psychological Education}

\section{The Meaning of Music Psychological Education}

The meaning of music psychology education Music psychological education refers to the basic music teaching classroom as the basis, with music subject knowledge as a secondary line to help students in the understanding, learning and creative music in the process, the subjective content and music content Up, so as to cultivate students' healthy mental state and psychological adjustment ability. Music psychology education is not a simple combination of music education and mental health education, but in the student's mental state, the artistic sense of music and its own psychological construction and development to achieve a high degree of unity. Music psychology education is not only to cultivate students' musical skills or to cultivate students' healthy mental state, but to combine the two together and let the music go deep into the students' mental state construction....

\section{The Role of Music Psychology Education}

Music psychology education can make students feel the beauty, find beauty and create beauty through the training of students 'feelings and aesthetics, so as to cultivate students' healthy aesthetic taste to help students have higher aesthetic taste. Second, the process of music psychological education is different from other subject class, more relaxed, students can in the process of music psychology education, access to the harmonious development of physical and mental. Finally, music psychology education can also help students to develop self-education ability, through students in music learning to cultivate the initiative, to promote students in other subjects of learning and their own lives to play their own subjective initiative.

\section{Analysis of Students' Common Psychological Problems}

Students in the learning process, the main will have three aspects of psychological problems, one is due to learning pressure caused by weariness, the second is the social problems with the students when the third is in the process of growth in the common rebellious problem. In the process of music psychology education, teachers should focus on the specific psychological problems of students to set up and guide. The following is an analysis of the common psychological problems of students in this paper:

\section{Burnout and weariness caused by learning stress}

In an increasingly competitive society, students are faced with a great deal of education and future employment pressures. If the learning pressure is too serious, students are prone to some loss and anxiety.

\section{Social issues}

In the school, students need to communicate with teachers and classmates. And the group, each role of words and deeds will give students the psychological state of the impact, students often encounter some confusion among the confusion. Students tend to come from peers and teachers to understand and support, but if you encounter a lack of patience and confidence in the teacher, students are easy to lose confidence, lack of courage, and gradually dare not to communicate with people around. Second, in the interaction with the students, if the encounter is not smooth, the students are easy to feel lost and lonely. Such negative emotions will have a negative impact on the mental health of students.

\section{Rebel psychology}

Students in the learning stage, almost all will encounter a period of rebellious time. Because students are not old, social experience is too small, in the face of difficult problems or the choice of the predicament, often into a confused and helpless, followed by a variety of psychological problems. While the students are too small age, lack of adequate emotional control. Those students with 
insufficient compression capacity will often have a low mood at this stage, and even a slump in the situation.

\section{The expectation of music teacher in music psychology}

The traditional music curriculum for the music teacher's request can no longer meet the requirements of music psychology education classroom. In the process of music psychology teaching, teachers not only let students understand and master the relevant music knowledge, but also need to guide students in the process of learning related value to reflect, to help students build a complete and positive psychological structure, promote Students continue to pursue life. The following is the music psychology for music teachers expect some of the analysis:

\section{Reform their own position}

Music teacher traditional teaching music knowledge of the identity, it must be difficult to meet the requirements of music psychological education. In the music psychology education classroom, the teacher should be positioned itself as a means to help students to carry out the construction of healthy mental state of the mentor, or personality perfect shape. Because in the music psychological education activities, music teachers for their own positioning will be on the aesthetic cultivation of students and character development have a direct impact. Music teachers are the leaders of students' music learning. Only music teachers have a clear understanding of their own position, so that they can help students to use music for psychological construction from the fundamental consciousness.

\section{Update the teaching objectives}

Music classroom in the music education, music teachers need to adjust the teaching objectives, to enable students to master the relevant music knowledge is no longer the goal of the classroom. Teachers not only need to spread the relevant music knowledge, but also to guide students step by step along the right path towards the overall goal. The overall goal is that students through music learning and creation, to build their own complete and positive psychological state. The teacher can not pass a section or two courses, let the students have a permanent positive attitude. Therefore, teachers need to be based on the overall teaching objectives, split into each lesson or every stage of learning a small goal to help and guide students to develop in an all-round way, and ultimately have a positive attitude and self-regulation ability.

\section{Continue to take the initiative to enhance their ability}

Music teacher is the student to learn music promotion, is the student learning guide and cultivate. In modern society, science and technology and music knowledge are changing, teachers need to keep up with the trend, improve their knowledge reserves and comprehensive quality. Because the classroom after all is the main way students get relevant knowledge. Therefore, teachers of music education classroom, need to continue to take the initiative to take up new knowledge and understanding of the current new trend, to enrich their own knowledge reserves, to be able to students enough fresh and comprehensive knowledge. Before becoming a leader in the classroom, the teacher must first walk in the forefront of society, so the music teacher needs to constantly learn new knowledge and sum up their own experience, making the teaching effect can be better.

\section{Enhance their own qualities}

In the process of learning, the student's self-quality for its psychological state is relatively large, and students by the teacher's quality and temperament of the direct impact is relatively large. So the teacher is a mirror in the student's learning process. In order to improve the overall quality of students, teachers should first pay attention to improve their own quality, in the face of the unexpected situation in the classroom, calm and fast to choose the most correct way or means to deal with the relevant issues, In the face of major decisions do not panic. Music teaching process, but also the 
teacher's music literacy to the students to pass a process, as long as the teacher has a high quality, students can more deeply appreciate the influence of the music environment and the art of musical appeal, by feeling the beauty of music, to purify Mind, to cultivate their own sentiments, while to cultivate open-minded and calm state of mind.

\section{Attention to teaching methods}

The unique charm of music education is to be able to become a bridge of emotion, the teacher and students close together. Therefore, teachers in the teaching, the need for a variety of flexible education, to help students in the process of learning more emotional experience, making the students thinking and imagination can be further inspired. Many students because of age, experience is still shallow, but the curiosity is very strong. By feeling the music, students can appreciate the different emotions in life, help to develop their calm state of mind to help them achieve a more open-minded state. So the music teacher's teaching method in which played a very important role. If it is too common teaching methods, students are difficult to learn in the process of interest, and even easy to produce tired of classroom psychology. Teachers should use some lively teaching methods, such as sub-groups to play games, etc., to ensure the effect of classroom teaching.

\section{Pay attention to communication skills}

In the student community, because they are not the same character, not all students are willing to communicate with the teacher or parents. Therefore, the music psychology teachers need to communicate with students, for each student is not the same character using different communication skills, and students to establish a good relationship between teachers and students. Good teacher-student relationship is the music teacher's education work carried out smoothly, but also the guarantee of music psychological education. Therefore, in the face of temper more students, the teacher can not be emotional, to maintain a good emotional state and optimistic mood, with love and patience to accommodate and infected students. Teachers in the process of communication, understand the reluctance to reveal the real needs of students after the students to help them.

\section{Organize extracurricular activities, pay attention to student life}

Students' performance on the classroom does not necessarily be consistent with their state of life. Therefore, the music psychological education teachers need to organize some after-school activities, meticulous observation of students in the state of life, to determine the student's learning outcomes. Teachers can also work with students to cultivate a variety of leisure hobbies, so that students amateur life as much as possible, so that both teachers can improve the creativity in the work, but also to guide students to reach a wide range of life in all aspects. Teachers can also lead students to participate in some activities similar to the concert, so that students really soaked in the music of the ocean, enjoy the tranquil mood, improve mental health.

\section{Conclusions}

The process of education is to people to shape the process of people, so the music psychology education teachers also need to have excellent professional ethics and noble character. And music culture itself belongs to the elegant artistic characteristics, therefore, music psychology teachers need to have a sound personality. Music teacher as a beauty of the communicator, words and deeds affect the students to form a healthy state of mind and develop their own psychological adjustment ability of the process. Therefore, teachers of music psychology education need to re-positioning their own position and the small goal of reforming classroom teaching before the formal commencement of teaching. In the process of teaching, we must constantly improve our ability and improve our own accomplishment, supplemented by the appropriate teaching method And effective communication skills, and in the spare time to do more activities to help students in the study and life, have a healthy and complete psychological state. 


\section{References}

[1] Long Yajun. On the Expectation of Music Teachers in Music Psychology Education. Journal of Educational Science of Hunan Normal University,2007,(03):51-54.

[2] Wei Wei. On the role of music education in cultivating middle school students' mental health. Qufu Normal University,2009.

[3] Hu Xiao. On the Importance of Classical Music Education and Popularization to the Current Development of College Students' Psychological Health. Theatrical family,2014,(07):117.

[4] Wang Fusheng. On the Optimizing Effect of Music Education on the Psychological Quality of Adolescents. Journal of Tianjin Academy of Educational Science,2006,(04):82-83.

[5] Chen Tingting. On the Professional Role Orientation of Middle School Music Teachers.Hunan Normal University,2014. 